\title{
Stalder, F. (2018). The digital Condition. Cambridge: Polity Press.
}

\author{
Helena Barranha \\ Instituto Superior Técnico, Universidade de Lisboa, Portugal/ \\ Instituto de História da Arte, Faculdade de Ciências Sociais e Humanas, Universidade Nova de Lisboa, Portugal
}

Ao longo das últimas décadas, a palavra "digital" tornou-se recorrente nos mais diversos discursos e meios de comunicação. Usada tanto como substantivo como para qualificar diferentes ações, produtos e experiências, passou a fazer parte do léxico quotidiano surgindo, ao mesmo tempo, como palavra-chave em inúmeros projetos e artigos científicos. Em conjunto, estas distintas abordagens contribuíram para um consenso generalizado em torno da ideia de que as tecnologias digitais condicionam todas as esferas da vida contemporânea. Mas o que caracteriza, exatamente, a "condição digital" em que vivemos? Se a questão era já pertinente em 2016, quando a primeira edição do livro de Felix Stalder foi lançada, a sua relevância é hoje ainda mais evidente.

Num registo e num ritmo sem precedentes, a pandemia de Covid-19 obrigou uma larga percentagem da população mundial a transferir, para meios digitais e em rede, muitas das atividades profissionais, sociais e familiares que, até aqui, decorriam sobretudo em contextos presenciais. Pessoas, instituições e empresas tiveram assim de adaptar-se, num período extraordinariamente curto, a rotinas de teletrabalho, métodos ensino à distância e dinâmicas de socialização por videoconferência. Neste cenário, cujos contornos e impactos estão ainda por apurar, The digital condition fornece várias referências que nos permitem compreender melhor a situação em que nos encontramos, assim como refletir sobre os respetivos antecedentes e possíveis desenvolvimentos.

Esta obra reflete o percurso profissional e académico do autor e o trabalho de investigação que tem vindo a realizar, desde os anos 1990, numa área de cruzamento entre a cultura, a política e a tecnologia. A par da sua atividade como professor de cultura digital na Universidade de Artes de Zurich, Felix Stalder colabora com o Institute for New Cultural Technologies e com o Technopolitics Group de Viena, dedicando-se a temas como os novos modos de produção colaborativa (commons), a sociedade de controlo, os direitos de autor e a transformação da subjetividade'.

A estrutura do livro, assente em apenas três capítulos intitulados "evolução", "formas" e "política", espelha a clareza com que o autor elabora todo o seu discurso. $\mathrm{Na}$ introdução, Stalder apresenta brevemente o conteúdo de cada um destes tópicos e revela também os pressupostos e os objetivos deste estudo, focado nos "desenvolvimentos culturais do Ocidente (transatlântico)" (p. 4) e em "dinâmicas abertas que podem ainda ser influenciadas" (p. 6).

'Ver autobiografia do autor, disponível em http://felix.openflows.com/node/4 
Em linha com textos de referência, no campo da teoria e da história da cultura contemporânea - bastaria pensar em A condição pós-moderna de Lyotard (1979) - Stalder constrói a sua reflexão a partir da identificação de um sistema unitário, um novo quadro socio-cultural que descreve como "condição". Colocar o problema no singular implica, desde logo, reconhecer um conjunto de formas ou características comuns ao amplo espectro de transformações e manifestações culturais ocorridas nas últimas décadas. Ao longo do livro, o autor demonstra, de modo convincente, esta hipótese interpretativa. Nas primeiras páginas, Stalder discute também o conceito de "digital", notando que os novos média são tecnologias relacionais cuja evolução e alcance ultrapassa a estrita dimensão tecnológica:

por conseguinte, o "digital" denota o conjunto de relações que, com base nas infraestruturas das redes digitais, afeta hoje a produção, o uso e a transformação de bens materiais e imateriais, assim como a constituição e a coordenação de atividades pessoais e coletivas. Nesse sentido, o foco está menos no domínio de um certo tipo de artefactos tecnológicos - o computador, por exemplo - e ainda menos na distinção entre "digital" e "analógico", "material" e "imaterial". Mesmo na condição digital, o analógico não desapareceu. Pelo contrário, foi reavaliado e até parcialmente atualizado. Além disso, o imaterial nunca existe inteiramente sem materialidade. (pp. 8-9)

Para além de evidenciar a crescente hibridização entre digital e analógico, material e imaterial, o autor considera que os atributos geralmente associados ao digital - imaterialidade, perfeição e virtualidade - perderam validade (p. 9). Stalder aproxima-se aqui do conceito de "pós-digital", citando autores como Kim Cascone e Florian Cramer (p. 9). Curiosamente, não é referida Marisa Olson, artista, curadora e crítica de arte que, desde 2006, contribuiu decisivamente para cunhar o termo "pós-internet", entendido como "um momento, uma condição, uma propriedade e uma qualidade que abrange e transcende os novos média" (Olson, 2011/2015, p. 133).

A globalização dos meios de comunicação de massa está em foco no primeiro capítulo do livro - "Evolution" - no qual Stalder defende que a "Galáxia Gutemberg", teorizada por Marshall McLuhan na década de 1960, foi substituída por uma nova realidade, marcada pela crise das formas e instituições culturais previamente estabelecidas e pela sua gradual substituição por novas vias, que têm contribuído para "novas dinâmicas políticas contraditórias e conflituais" (p. 4). Nesta síntese histórica, analisa-se a emergência da economia do conhecimento, sucessivamente associada a noções como "sociedade pós-industrial" (anos 1970), "sociedade da informação" (anos 1980) e "sociedade em rede" (anos 1990) (p. 17).

Todavia, importa notar novamente que, segundo o autor, a atual "condição digital" não deve ser vista como uma mera consequência de avanços tecnológicos. Contrariando os discursos tecnocráticos dominantes, o autor parece subscrever a ideia de que "os sistemas tecnológicos produzem-se socialmente e a produção social é determinada pela 
cultura" (Castells, 2001/2004, p. 55). Esta visão tem vindo a ser corroborada por vários investigadores, como Charlie Gere que, no livro Digital culture, defende que "o digital não diz apenas respeito aos efeitos e às possibilidades de uma tecnologia específica. Engloba e define formas de pensar e de fazer que estão incorporadas nessa tecnologia e que tornam o seu desenvolvimento possível" (Gere, 2002/2008, p. 17). Stalder volta, aliás, a este assunto no final do segundo capítulo, acrescentando que:

em rigor, é impossível sustentar uma distinção categórica entre processos sociais que ocorrem dentro e através de infraestruturas tecnológicas e processos técnicos que são socialmente construídos. Em ambos os casos, os atores sociais tentam concretizar seus próprios interesses com os recursos à sua disposição. Os métodos (ou tentativas) de concretização, os recursos disponíveis e a formulação de interesses influenciam-se mutuamente. Os recursos tecnológicos estão inscritos na formulação de objetivos. Estes abrem campos de imaginação e desejo, que por sua vez inspiram o desenvolvimento técnico. (p. 103)

Outro ponto particularmente interessante na primeira parte do livro diz respeito à "culturalização do mundo", destacando-se a forma como a sociedade de consumo evoluiu em direção a uma crescente valorização e exploração comercial das dimensões culturais e afetivas (p. 35). Paralelamente, a digitalização e as dinâmicas potenciadas pelas redes criaram uma quantidade infinita de novos conteúdos ("matéria-prima") e abriram caminho para que a apropriação e a recomposição se tornassem "métodos gerais de produção cultural" (p. 40).

Ao apresentar a "condição digital" como uma "constelação cultural que determina todas as áreas da vida" contemporânea (p. 57), Stalder identifica um conjunto de três características preponderantes e ubíquas: referentiality, communality e algorithmicity, que poderíamos traduzir como referencialidade, comunalidade e algoritmicidade, analisados detalhadamente no segundo capítulo, com o título "Forms".

Referencialidade, comunalidade e algoritmicidade tornaram-se as formas características da condição digital porque cada vez mais pessoas - em cada vez mais segmentos da vida e através de tecnologias cada vez mais complexas - participam ativamente (ou obrigatoriamente) na negociação do significado social. Elas reagem, desta forma, às solicitações de uma esfera de informações caótica e avassaladora, acabando por contribuir, assim, para acentuar a sua expansão. (p. 125)

O facto de os públicos terem passado a assumir um papel cada vez mais ativo nos processos de produção e difusão cultural criou também novos desafios para as estruturas institucionais. Para além de digitalizarem e disponibilizarem online os seus acervos, museus, arquivos e outras instituições culturais investem hoje em atividades orientadas para um maior envolvimento criativo dos públicos, como sucede, por exemplo, com a iniciativa "Rijksstudio", promovida pelo Rijksmuseum de Amesterdão (pp. 76-77). 
Por outro lado, as práticas culturais baseadas na auto-referenciação, que constituem um dos principais catalisadores das redes sociais, são indissociáveis de novas dinâmicas de grupo, baseadas num modelo de cooperação flexível. De acordo com o autor, mais do que os indivíduos, são as novas formações comunitárias que assumem e dinamizam três funções essenciais para a "condição digital" - seleção, interpretação e capacidade constitutiva de agir - sendo, portanto, determinantes para a cultura contemporânea (pp. 80-81, 93).

Transversal a este contexto, a algoritmicidade surge como resposta à incapacidade humana para gerir as quantidades incomensuráveis de dados que circulam hoje, nas redes, e que são diariamente produzidas por pessoas e máquinas.

$\mathrm{Na}$ base ou à frente dos mecanismos sociais da produção cultural descentralizada e em rede, existem processos algorítmicos que pré-classificam volumes imensuravelmente grandes de dados e os convertem em formatos que podem ser apreendidos por indivíduos, avaliados por comunidades e investidos de significado. (p. 103)

Nos últimos anos, vários autores têm problematizado o papel da inteligência artificial e, em particular, o poder dos algoritmos, "o método através do qual acedemos a conteúdos na web e que colonizou quase todos os aspetos da nossa vida quotidiana" (Pepi, 2011 , s. p.). Felix Stalder salienta que os algoritmos se têm tornado progressivamente mais complexos e dinâmicos e adverte que, ao incorporarem elementos de personalização e contextualização, estes processos automáticos são cada vez mais instáveis, opacos e ambivalentes. Entre os exemplos apontados, destaca-se o algoritmo de pesquisa do Google, sujeito a permanente revisão e adaptado ao perfil de cada utilizador. Consequentemente, constata-se que estes algoritmos já não visam representar o mundo, mas sim gerar uma realidade que é filtrada e apresentada de modo personalizado (p. 116).

Este poder tendencialmente ilimitado que é conferido aos mecanismos automáticos para organizarem o mundo em que vivemos comporta, obviamente, muitos riscos, sobretudo quando se verifica que as principais plataformas digitais que utilizamos nomeadamente o Google, o Facebook, o Twitter ou o Instagram - são tuteladas por um grupo restrito de agentes económicos privados que atuam à escala global. Neste contexto, o funcionamento das redes está intimamente ligado ao efeito de monopólio (p. 143), um sistema detido por quem controla não só os dados, mas também os algoritmos que os extraem, ordenam e revelam.

O facto de estes problemas serem ainda insuficientemente debatidos e sujeitos a escrutínio público confere uma especial importância ao terceiro e último capítulo do livro, dedicado à dimensão política da "condição digital". Nesta parte final, Felix Stalder confronta duas tendências opostas e já amplamente disseminadas, a nível mundial: pós-democracia e commons ${ }^{2}$. Segundo ao autor, estamos perante duas vias alternativas que sugerem uma superação da atual crise da democracia liberal e que podem representar novos projetos políticos (p. 7).

\footnotetext{
${ }^{2}$ Opta-se, aqui por deixar a palavra na versão inglesa por não existir, em português, um termo rigorosamente equivalente.
} 
A primeira [pós-democracia] move-se em direção a uma sociedade essencialmente autoritária, enquanto a segunda [commons] se move em direção a uma renovação radical da democracia, ampliando o âmbito da tomada de decisão coletiva. Ambos os casos envolvem mais do que algumas pequenas alterações na ordem existente. Verifica-se, sobretudo, que ambos estão a conduzir a uma nova constelação política que ultrapassa a democracia representativa liberal. (p. 127)

No ponto dedicado à pós-democracia, Stalder alerta para a inevitabilidade de as desigualdades no acesso à informação gerarem desequilíbrios de poder (p. 135). Este desequilíbrio reflete-se, desde logo, no modo como os utilizadores das plataformas digitais têm acesso apenas a uma pequena parte dos dados que lhes dizem respeito, enquanto os programadores e analistas informáticos ao serviço dos grandes operadores multinacionais têm acesso a toda a informação (p. 135). Neste cenário, existem vários indícios que as redes sociais têm capacidade (e frequentemente exercem-na) para manipular os utilizadores, designadamente para fins políticos e comerciais. $\mathrm{O}$ argumento tecnocrático (e antidemocrático) de que "não existe alternativa" para esta manipulação apoia-se normalmente na ideia falaciosa que o ambiente informacional em que nos movemos deve ser otimizado através de mecanismos de controlo que nos são alheios (p. 149). Simultaneamente:

[o termo] "pós-democracia» refere-se a estratégias que neutralizam a capacidade enormemente expandida de comunicação social, desconectando a possibilidade de participar em algo da capacidade de tomar decisões sobre isso. Todos podem expressar sua opinião, mas as decisões são tomadas por um pequeno número de pessoas. (p. 6)

Apesar destas ameaças, Stalder lembra que "todas as formas de poder motivam correspondentes formas de resistência" (p. 149) e aponta os projetos colaborativos em torno de interesses e objetivos comuns (commons) como a prova de que existem, efetivamente, alternativas. O autor começa por referir que esta via não é nova nem especificamente ocidental explicando que, embora o termo commons só tenha sido aplicado a partir da segunda metade da década de 1990, este conceito estava já implícito nas experiências pioneiras de criação de software livre, desde os anos 1980 (p. 156). Para ilustrar e discutir esta noção, o autor examina exemplos mais recentes, como a Wikipedia, a organização não-governamental Creative Commons ou o projeto colaborativo OpenStreetMap.

As práticas socioculturais baseadas na partilha e na construção colaborativa ganharam um novo significado em tempos de pandemia global. Mais do nunca, verifica-se que as redes não se limitam a representar a realidade; elas condicionam e modelam a realidade individual e coletiva em que vivemos. A par da dimensão informativa das redes, durante o encerramento temporário dos seus espaços físicos, as instituições culturais reforçaram a sua presença online, difundindo digitalmente o seu património e as suas 
produções. Concertos, peças de teatro, visitas guiadas, exposições, conferências, programas educativos e muitas outras atividades passaram a estar disponíveis na internet. À semelhança das instituições, também os próprios artistas passaram, cada vez mais, a utilizar as redes como espaço criativo, performativo e comunicativo. Neste contexto, as redes assumiram todo o seu potencial como palco preferencial para o desenvolvimento e apresentação de propostas artísticas diversas, um lugar de encontro preferencial entre os criadores e os seus públicos.

No entanto, e apesar da inevitabilidade de recorrermos mais às redes num tempo em que a nossa liberdade é limitada pela ameaça do coronavírus, importa manter algum distanciamento crítico. Torna-se, agora, particularmente oportuno trazer para o debate algumas das questões formuladas no livro The digital condition, nomeadamente: poderão as redes detidas pelos grandes monopólios ser verdadeiramente reconhecidas e apropriadas como espaço público? Conclui-se, assim, que a problematização em torno da "condição digital" constitui um campo ainda aberto para novas pesquisas e reflexões. O livro de Felix Sadler é, sem dúvida, um estimulante e sólido ponto de partida para essa discussão que, desejavelmente, deverá mobilizar os mais diversos sectores da sociedade.

\section{REFERÊNCIAS}

Castells, M. (2001/2004). A galáxia internet. Reflexões sobre internet, negócios e sociedade. Lisboa: Fundação Calouste Gulbenkian.

Gere, C. (2002/2008). Digital culture. Londres: Reaktion Books.

Lyotard, J.-F. (1979). A condição pós-moderna. Paris: Les Éditions de Minuit.

Olson, M. (2011/2015). Pós-internet: a arte depois da internet. In H. Barranha, S. S. Martins \& A. P. Ribeiro (Eds.), Museus sem lugar: ensaios, manifestos e diálogos em rede (pp. 123-136). Lisboa: Instituto de História da Arte, FCSH Universidade Nova de Lisboa. Retirado de http://unplace.org/sites/default/ files/museus_sem_lugar.pdf

Pepi, M. (2011) Iconology in the age of the algorithm. Artwrit, VI. Retirado de http://www.artwrit.com/article/ iconology-in-the-age-of-the-algorithm/

\section{NOTA BIOGRÁFICA}

Helena Barranha é doutorada em Arquitetura (Faculdade de Arquitetura - Universidade do Porto) e Mestre em Gestão do Património Cultural (Universidade do Algarve). É Professora Auxiliar no Instituto Superior Técnico, Universidade de Lisboa e investigadora no Instituto de História da Arte, Faculdade de Ciências Sociais e Humanas, Universidade Nova de Lisboa. Foi diretora do Museu Nacional de Arte Contemporânea - Museu do Chiado, de 2009 a 2012, e coordenadora do projeto "unplace: Um Museu sem Lugar", entre 2014 e 2015. As suas atividades de investigação centram-se atualmente no património cultural, na arquitetura de museus e nas culturas digitais, temas sobre os 
quais tem realizado várias conferências e publicações, tanto em Portugal como noutros países. É membro da Associação Acesso Cultura, do ICOM-Portugal e da European Network Association.

ORCID: https://orcid.org/oooo-0003-0250-1020

Email: helenabarranha@tecnico.ulisboa.pt

Morada: Instituto Superior Técnico, DECivil - Arquitectura, Av. Rovisco Pais, 1, 1049-001, Lisboa, Portugal

Submetido: 05/04/2020

Aceite: 06/05/2020 